\title{
Studies on the effects of superficial strengthening with FRCM system on compressive strength of AAC masonry
}

\author{
Lukasz Drobiec ${ }^{1}$, Wojciech Mazur $^{2}$, Remigiusz Jokiel ${ }^{3}$ \\ ${ }^{1}$ Department of Building Structures; Faculty of Civil Engineering; Silesian University of Technology; \\ Akademicka 2 St., 44-100 Gliwice, Poland; \\ lukasz.drobiec@polsl.pl (iD)0000-0001-9825-6343 \\ ${ }^{2}$ Department of Building Structures; Faculty of Civil Engineering; Silesian University of Technology; \\ Niedobczycka 2 St., 44-100 Gliwice, Poland; \\ wojciech.mazur@polsl.pl (iD)0000-0001-6382-1496 \\ ${ }^{3}$ BUDINŻ PB Sp. z o.o. Sp.k.; Niedobczycka 2 St., 44-290 Jejkowice, Poland; \\ remigiusz.jokiel@gmail.com
}

\begin{abstract}
This paper describes results from studies on the effects of superficial strengthening with FRCM system on compressive strength of autoclaved aerated concrete (AAC) masonry. Tests were carried out on models without any strengthening, strengthened at one or both sides. Two-side strengthened masonry demonstrated an increased compressive strength and deformability. Increased deformability was observed for one-side strengthened masonry when compared to tests on masonry without any strengthening.
\end{abstract}

Keywords: AAC blocks, compressive strength, FRCM system, superficial strengthening

\section{Introduction}

Repairs of cracked masonry walls are increasingly made using superficial strengthening [1] especially FRCM [2]-[5]. This repair system consists of high-performance mortar from cement binders and various additives, and grid made of carbon, glass, basalt, aramid, or other fibres. Factory-made mortar is physically and chemically compatible with the wall, especially the brick wall. There are no design guidelines consistent with Eurocodes. Thus, material tests must be performed in accordance with European standards, to develop suitable guidelines verified on big models under complex stress states.

It is apparent that the most effective use of superficial strengthening is observed for tensile forces which can be successfully verified by conducting tests on tensile strength of the wall by subjecting it to diagonal compression in accordance with the standard [6]. Such tests on evaluating the effects of superficial strengthening on tensile strength of AAC walls under diagonal compression have been already performed in the laboratory of the Faculty of Civil Engineering at the Silesian University of Technology [7]-[9]. However, it is important that 
not only vertical compressive stresses occur under axial compression, but horizontal tensile stresses are observed as well.

Currently, new tests are performed to determine the effect of superficial strengthening with FRCM system on compressive strength of AAC masonry with one-side and two-side strengthening. The research programme includes tests on compressive strength of masonry walls in accordance with the standard [10], their tensile strength under compression by the standard [6] and their shear strength [11]. Additionally, tests are planned to evaluate the effect of superficial strengthening on compressive strength of walls with a vertical crack and strengthened in four sides, and walls with additional mechanical anchorage of superficial strengthening.

\section{Research tests}

\subsection{Aim and scope of tests}

The aim of tests described in this paper was to determine the effects of superficial strengthening with FRCM system on compressive strength of AAC masonry. Observation of behaviour, cracking pattern and failure of test elements was the intermediate purpose of the tests. The scope of performed tests included masonry walls without any strengthening, strengthened at one side or both sides. Compressive strength of the masonry was performed in accordance with [10] PN-EN 1052-1.

\subsection{Research models}

The masonry was made of SOLBET OPTIMAL blocks with dimensions $l \times t \times h=590 \times 180 \times 240 \mathrm{~mm}$, density class of 600 and normalized compressive stress $f_{\mathrm{b}}$ equal to $4.0 \mathrm{~N} / \mathrm{mm}^{2}$ [12]. White cement-based mortar for thin joints from SOLBET company - identified by the symbol 0.1 , nominal class M5, compressive strength $f_{\mathrm{m}}$ equal to $6.1 \mathrm{~N} / \mathrm{mm}^{2}$ [12] was used in test models.

Dimensions of test specimens were determined in accordance with [10]. The width of test specimens was equal to two masonry units, and their height corresponded to 5 masonry units. Dimensions of test specimens are shown in Fig. 1a. Figure 1b illustrates some tested units.

a)

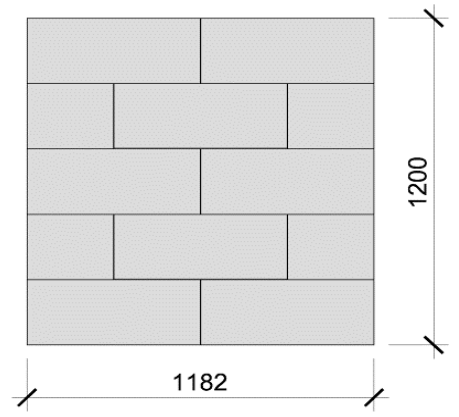

b)

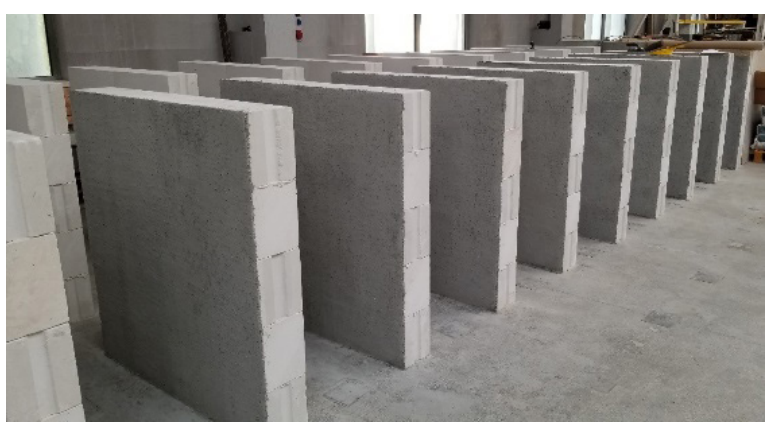

Fig. 1. Test specimens: a) arrangement of masonry units in the research model and its dimensions, b) strengthened test specimens of S1F1 and S1F2 series. Source: own study 
Test specimens were prepared on the flat surface of the strong floor in the Laboratory of the Civil Engineering Faculty, Silesian University of Technology, built on a thin sand bed. After applying a course of masonry units, bed surfaces were smoothed with planes to level minor irregularities of the surface, and then cleaned with a brush. Mortar was placed only on the bed surface with a special trowel $180 \mathrm{~mm}$ wide (head joints were unfilled). Test specimens were covered with $0.2 \mathrm{~mm}$ thick PE foil for the first three days to protect them against excessive drying. After that time, test specimens were stored under dry air conditions in the laboratory, at temperature $\geq 15^{\circ}$ and humidity $\leq 65 \%$ until they were subjected to tests.

After 28 days, lateral surfaces of strengthened models were coated with ready-mixed mortar PBO-MX GOLD MURATURA, and the grid PBO-MESH GOLD 70/18 was laid in it. Then, the surface layer of ready-mixed mortar PBO-MX GOLD MURATURA was placed.

The testing programme involved 18 test models (Table 1). The first series included six reference models marked as S1N. The second series marked as N1F1 included six models strengthened on one side, and the one marked as S1NF2 embraced other six models strengthened on both sides.

Table 1. Marking of test series. Source: own study

\begin{tabular}{ll}
\hline Series & Number of test specimens \\
\hline S1N Unstrengthened test specimens & 6 \\
\hline S1F1 One-side strengthened test specimens & 6 \\
\hline S1F2 Two-side strengthened test specimens & 6 \\
\hline TOTAL & 18 \\
\hline
\end{tabular}

\subsection{Testing technique}

Tests were performed on test specimens after at least 28 days from finishing works. Tests were conducted in a hydraulic press with the compressive force of $200 \mathrm{~T}$. Test specimens were placed between platens of the hydraulic press, in the central position, without providing eccentricity. There was a full contact between the top and bottom surface of test specimens and platens of the universal testing machine.

During tests, a dynamometer measured compressive force with the accuracy of $0.001 \mathrm{kN}$, and inductive sensors measured horizontal and vertical displacements with the accuracy of $0.002 \mathrm{~mm}$. Additionally, displacements were measured with a non-contact optical system Aramis. For that purpose, surfaces of test specimens required painting in irregular designs and sticking points of measurements on the lateral surface of the test specimen. Dimensions of a measurement reference base for wall displacement were specified in accordance with [10]. That standard defines the base height equal to $1 / 3$ of the test specimen height and the width equal to $1 / 2$ of the test specimen width. For the arrangement of test specimens shown in Fig. 1, $1 / 2$ of its length is located on vertical joints. Previous experience of the authors showed that such a system could disturb the measurements.

Therefore, a decision was made to expand the horizontal base by $20 \mathrm{~mm}$ with reference to the base specified in the standard. The measurement reference base and the inductive sensor are illustrated in Fig. 2.

Vertical strains were measured to determine vertical stress $\sigma_{y}$ - vertical strain $\varepsilon_{y}$ relationship. And horizontal strains were used to determine Poisson's ratio $v$ of the masonry. 
a)

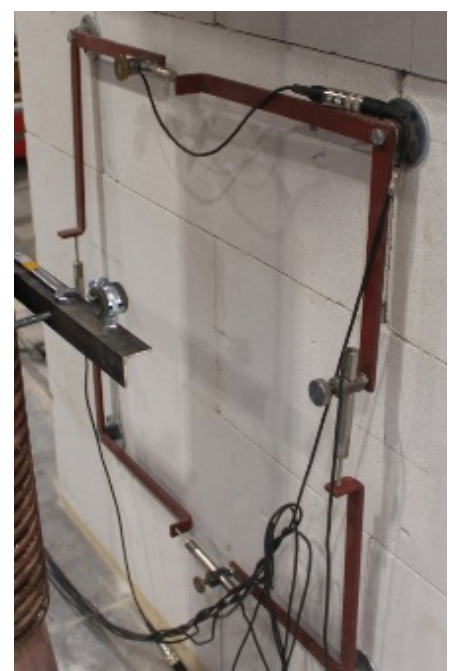

b)

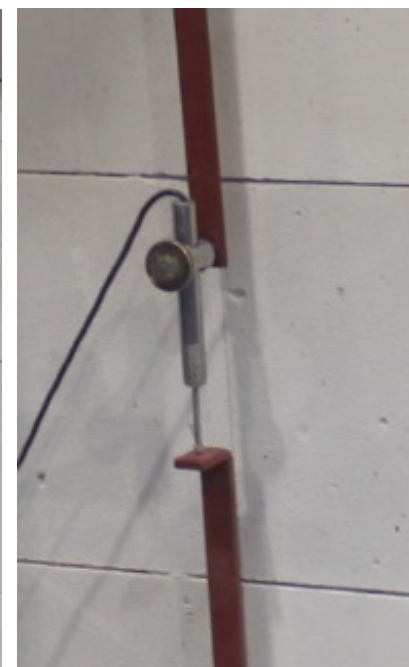

Fig. 2. The reference base for measuring displacement: a) view of the steel frame, b) inductive sensor. Source: own study

Prior to tests, each test specimen was carefully inspected for any possible damage. Then, each test specimen was measured with an accuracy to $\pm 1 \mathrm{~mm}$. All outer edges of test specimens were measured. Figure 3 presents one test specimen from each series in the test stand prior to tests. Photos illustrate frames for measuring displacements and irregular painting pattern for tactile measurement.

a)

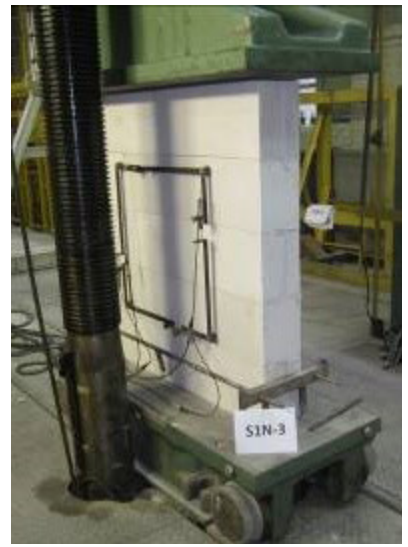

b)

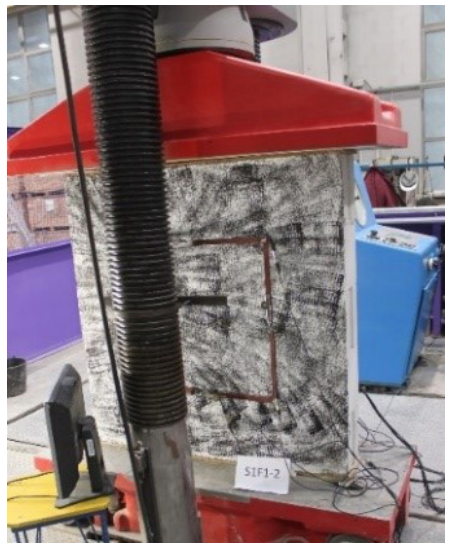

c)

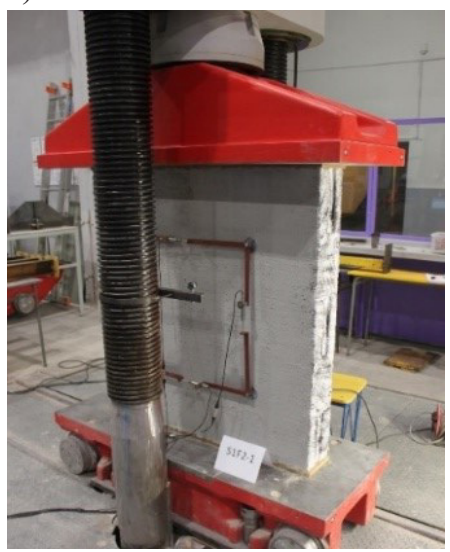

Fig. 3. Test specimens of each series prior to tests. Source: own study

Tests were conducted using an automated measuring stand. Displacements and compressive force were measured every $0.5 \mathrm{~s}$. The loading rate was applied in accordance with [10] to achieve the maximum force after 15-30 minutes from the commencement of loading. The force, at which the first visible crack occurred in the test specimen, was also recorded during tests. 


\section{Test results}

To determine values of cracking and failure stress, the force was divided by the measured cross-section area of the test specimen. Modulus of elasticity and Poisson's ratio were determined as a secant from the average value of deformations measured with sensors at stress equal to $1 / 3$ of maximum stress.

Table 2 presents values of stress, at which cracks were observed in test specimens, compressive strength, modulus of elasticity, and Poisson's ratio.

Table 2. Averaged test results for each series. Source: own study

\begin{tabular}{|c|c|c|c|c|c|}
\hline No. of series & & $\begin{array}{l}\text { Cracking } \\
\text { stress, } \\
\mathrm{N} / \mathrm{mm}^{2}\end{array}$ & $\begin{array}{l}\text { Maximum } \\
\text { stress, } \\
\mathrm{N} / \mathrm{mm}^{2}\end{array}$ & $\begin{array}{l}\text { Modulus of } \\
\text { elasticity, } \\
\mathrm{N} / \mathrm{mm}^{2}\end{array}$ & $\begin{array}{l}\text { Poisson's } \\
\text { ratio }\end{array}$ \\
\hline \multirow{9}{*}{$\begin{array}{l}\text { Unstrengthened } \\
\text { test specimens }\end{array}$} & S1N-1 & 2.35 & 2.95 & 1799 & 0.15 \\
\hline & $\mathrm{S} 1 \mathrm{~N}-2$ & 2.40 & 2.58 & 1766 & 0.19 \\
\hline & S1N-3 & 2.28 & 2.86 & 2143 & 0.19 \\
\hline & $\mathrm{S} 1 \mathrm{~N}-4$ & 2.25 & 2.56 & 2106 & 0.20 \\
\hline & S1N-5 & 2.42 & 3.58 & 2346 & 0.20 \\
\hline & S1N-6 & 2.40 & 3.29 & 2083 & 0.14 \\
\hline & Mean value & 2.35 & 2.97 & 2041 & 0.18 \\
\hline & Standard deviation & 0.07 & 0.40 & 221 & 0.03 \\
\hline & Coefficient of variation & $3 \%$ & $14 \%$ & $11 \%$ & $15 \%$ \\
\hline \multirow{9}{*}{$\begin{array}{l}\text { One-side } \\
\text { strengthened } \\
\text { test specimens }\end{array}$} & S1F1-1 & 2.45 & 2.74 & 2105 & 0.41 \\
\hline & S1F1-2 & 2.70 & 3.09 & 2218 & 0.38 \\
\hline & S1F1-3 & 2.50 & 2.79 & 1955 & 0.28 \\
\hline & S1F1-4 & 2.75 & 3.08 & 2125 & 0.42 \\
\hline & S1F1-5 & 2.80 & 3.15 & 1995 & 0.37 \\
\hline & S1F1-6 & 2.50 & 2.89 & 2269 & 0.46 \\
\hline & Mean value & 2.62 & 2.96 & 2111 & 0.39 \\
\hline & Standard deviation & 0.15 & 0.17 & 122 & 0.06 \\
\hline & Coefficient of variation & $6 \%$ & $6 \%$ & $6 \%$ & $16 \%$ \\
\hline \multirow{9}{*}{$\begin{array}{l}\text { Two-side } \\
\text { strengthened test } \\
\text { specimens }\end{array}$} & S2F1-1 & 2.75 & 3.13 & 2254 & 0.35 \\
\hline & S2F1-2 & 2.70 & 3.09 & 2265 & 0.38 \\
\hline & S2F1-3 & 2.85 & 3.36 & 2410 & 0.33 \\
\hline & $\mathrm{S} 2 \mathrm{~F} 1-4$ & 2.65 & 2.94 & 2257 & 0.46 \\
\hline & S2F1-5 & 2.75 & 3.15 & 1993 & 0.37 \\
\hline & S2F1-6 & 2.75 & 3.18 & 2144 & 0.23 \\
\hline & Mean value & 2.74 & 3.14 & 2221 & 0.35 \\
\hline & Standard deviation & 0.07 & 0.14 & 140 & 0.08 \\
\hline & Coefficient of variation & $2 \%$ & $4 \%$ & $6 \%$ & $21 \%$ \\
\hline
\end{tabular}

The course of failure was various for test specimens. In most test specimens, first cracks were observed before the failure of those test specimens (see Table 2). Cracks ran through 
joints and masonry units. Loosening of face parts of the masonry was also observed. Figures $4 \div 6$ present all lateral faces of destroyed elements.

a)

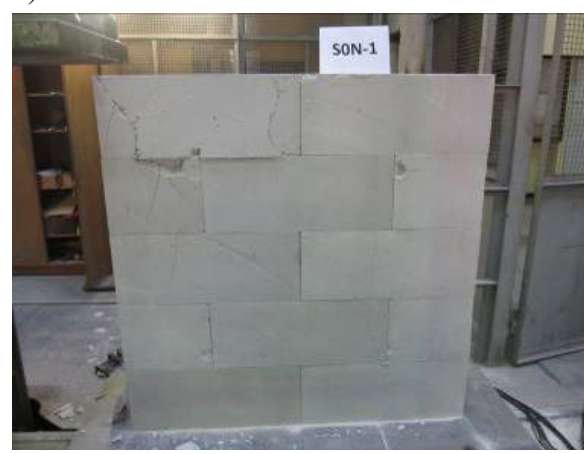

b)

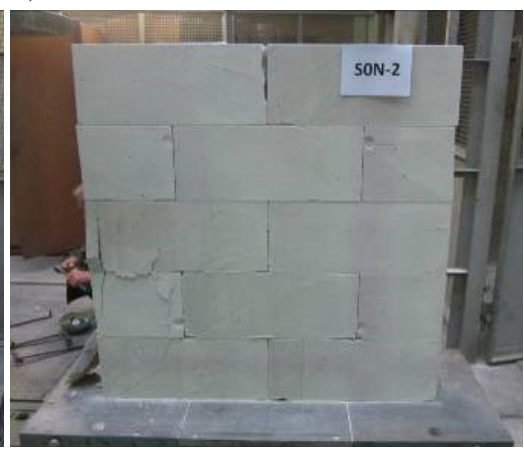

c)

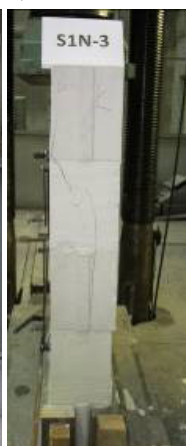

Fig. 4. Test specimens $\mathrm{S} 1 \mathrm{~N}$ after tests: a) S1N-1, b) S1N-2, c) S1N-3. Source: own study

a)

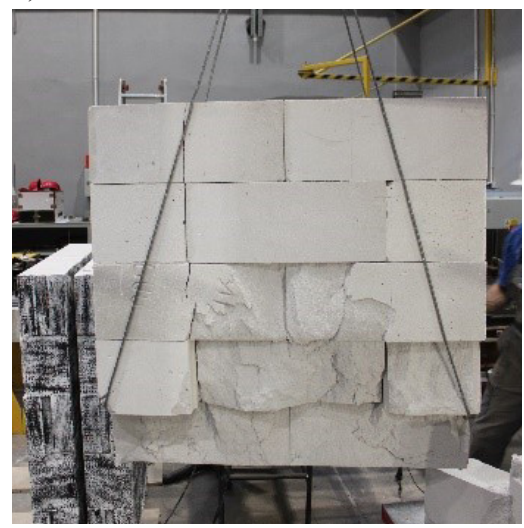

b)

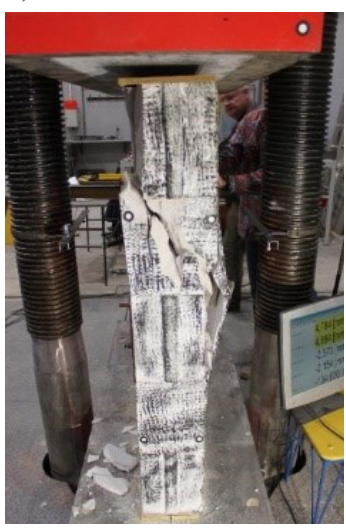

c)

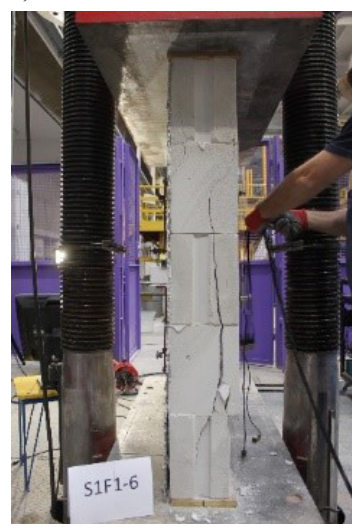

Fig. 5. Test specimens S1F1 after tests: a) S1F1-1, b) S1F1-5, c) S1F1-6. Source: own study

a)

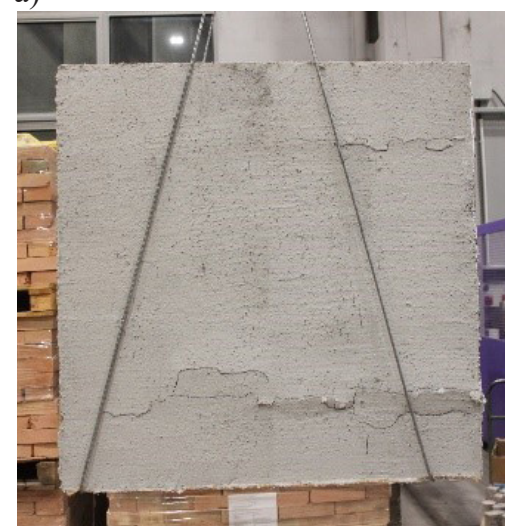

b)

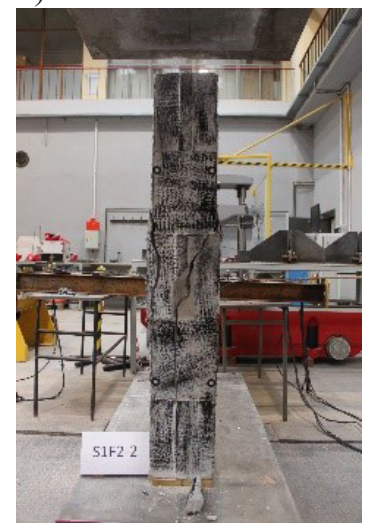

c)

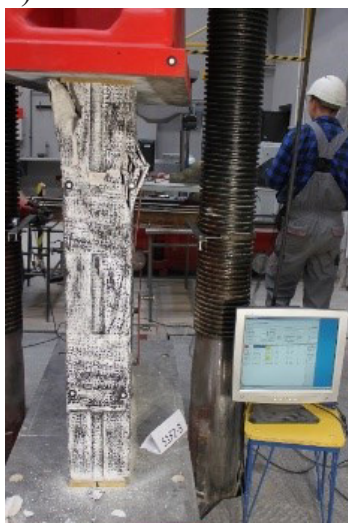

Fig. 6. Test specimens S1F2 after tests: a) S1F2-1, b) S1F2-2, c) S1F2-3. Source: own study 
Figure 7 shows the comparison of stress $\sigma_{\mathrm{y}}$ - vertical deformation $\varepsilon_{\mathrm{y}}$ and horizontal deformation $\varepsilon_{\mathrm{x}}$. relationships averaged for each series. Letter $\mathrm{y}$ in the description of diagrams in Fig. 7 denotes the vertical direction measurements, and the letter $\mathrm{x}$ denotes the horizontal one.

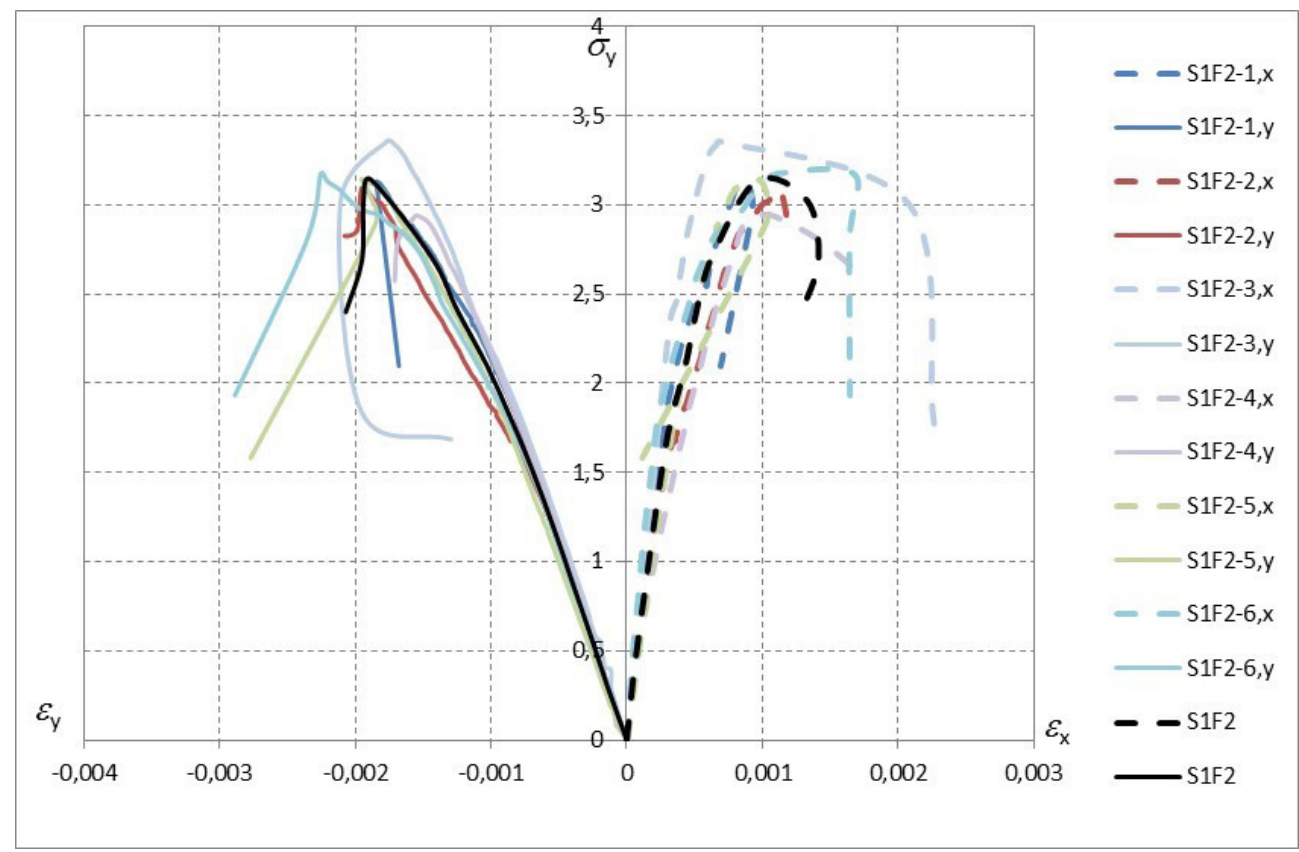

Fig. 7. Stress $\sigma_{\mathrm{y}}-$ vertical strain $\varepsilon_{\mathrm{y}}$ and vertical strain $\varepsilon_{\mathrm{x}}$ relationships averaged for each series. Source: own study

\subsection{Characteristic compressive strength of masonry acc. to [10] PN-EN 1052-1}

Characteristic compressive strength of masonry was determined within each series. That procedure was performed in accordance with [10] PN-EN 1052-1. The standard assumes that characteristic compressive strength of the masonry is a lower value of the averaged strength for a series divided by 1.2 or the minimum strength from a given series:

$f_{k}=\min \left\{\begin{array}{l}\frac{f}{1.2} \\ f_{i, \text { min }}\end{array}\right.$

where:

$f$-average compressive strength of the masonry for a given series (Table 2, Column 4);

$f_{\mathrm{i}, \min }-$ minimum compressive strength of a test specimen from a given series (Table 2 , Column 4).

Determined values of characteristic compressive strength for each series are presented in Table 3. First condition of Equation 1 was crucial for each series which shows a great homogeneity of tested walls. 
Table 3. Characteristic compressive strength of masonry acc to [10]. Source: own study

\begin{tabular}{ll}
\hline No. of series & $f_{\mathrm{k}, \text { test }}, \mathrm{N} / \mathrm{mm}^{2}$ \\
\hline S1N & 2.48 \\
Unstrengthened test specimens & 2.47 \\
\hline S1F1 & \\
\hline One-side strengthened test specimens & 2.62 \\
Two-side strengthened test specimens & \\
\hline
\end{tabular}

\subsection{Characteristic compressive strength of masonry acc. to [13] PN-EN 1990}

Characteristic compressive strength of masonry was determined within each series. That procedure was performed in accordance with [13] PN-EN 1990. Determined values of characteristic compressive strength for each series are presented in Table 4.

Table 4. Characteristic compressive strength of masonry acc to [13]. Source: own study

\begin{tabular}{ll}
\hline No. of series & $f_{\mathrm{k}, \text { test }}, \mathrm{N} / \mathrm{mm}^{2}$ \\
\hline S1N & 2.20 \\
Unstrengthened test specimens & 2.29 \\
\hline S1F1 & \\
\hline One-side strengthened test specimens & 2.60 \\
\hline Tw2 & \\
\hline
\end{tabular}

\section{Analysis of test results}

First cracks in test specimens of S1N series (unstrengthened) were observed at stress of $2.35 \mathrm{~N} / \mathrm{mm}^{2}$ which represented ca. $79.1 \%$ of maximum failure stress equal to $2.97 \mathrm{~N} / \mathrm{mm}^{2}$. Test specimens were cracked and destroyed due to internal cracks.

In test specimens of S1F1 series (one-side strengthened), first cracks developed at stress equal to $2.62 \mathrm{~N} / \mathrm{mm}^{2}$, which represented $88.5 \%$ of maximum failure stress $\left(2.96 \mathrm{~N} / \mathrm{mm}^{2}\right)$. Cracking stresses were greater by $10.3 \%$ compared to unstrengthened test specimens. Failure stresses were nearly the same.

Recorded cracking stress for test specimens of S1F2 series (two-side strengthened) was $2.74 \mathrm{~N} / \mathrm{mm}^{2}$, which represented $87.3 \%$ of failure stress $\left(3.14 \mathrm{~N} / \mathrm{mm}^{2}\right)$ and was greater by $14.2 \%$ and $4.4 \%$ compared to values for $\mathrm{S} 1 \mathrm{~N}$ and $\mathrm{S} 1 \mathrm{~F} 1$ series respectively. Failure stress of two-side strengthened test specimens was greater by ca. 5.4\% and 5.8\% compared to unstrengthened and one-side strengthened test specimens, respectively.

Strengthening caused an increase in modulus of elasticity by $3.4 \%$ for one-side strengthened test specimens, and by $8.1 \%$ for two-side strengthened test specimens, and in Poisson's ratio by $53.8 \%$ and $48.6 \%$ respectively.

Characteristic compressive strength values of the walls of series S1N, S1F1, and S1F2 which were determined in accordance with the standard [10] were equal to $2.48 \mathrm{~N} / \mathrm{mm}^{2}$, $2.46 \mathrm{~N} / \mathrm{mm}^{2}$ and $2.62 \mathrm{~N} / \mathrm{mm}^{2}$, respectively. Characteristic strength of the walls strengthened in one side was lower by $1 \%$ when compared to the walls without any strengthening. In the case of the walls with two-side strengthening, their characteristic strength was greater by $6 \%$ when compared to the walls without any strengthening. Different results were obtained for character- 
istic strength determined in accordance with the standard [13]. Strength values of $2.20 \mathrm{~N} / \mathrm{mm}^{2}$, $2.29 \mathrm{~N} / \mathrm{mm}^{2}$ and $2.60 \mathrm{~N} / \mathrm{mm}^{2}$ for the specimens of series S1N, S1F1, and S1F2 respectively were lower than the values determined under the standard [10] by ca. $11 \%$ for $\mathrm{S} 1 \mathrm{~N}, 7 \%$ for $\mathrm{S} 1 \mathrm{~F} 1$ and $1 \%$ for S1F2. Characteristic strength of the walls strengthened in one side, and two sides was greater by $4 \%$ and $18 \%$ respectively when compared to the unstrengthened walls.

No cracks on the strengthened surface were observed while analyzing results for strengthened models, measured with Aramis system based on digital image correlation. The analysis of displacement towards Z-axis, perpendicular to the strengthened surface of the masonry showed an increase in displacements in the bottom part of the test specimen which indicates the loosening of the strengthening from masonry units (Fig. 8).

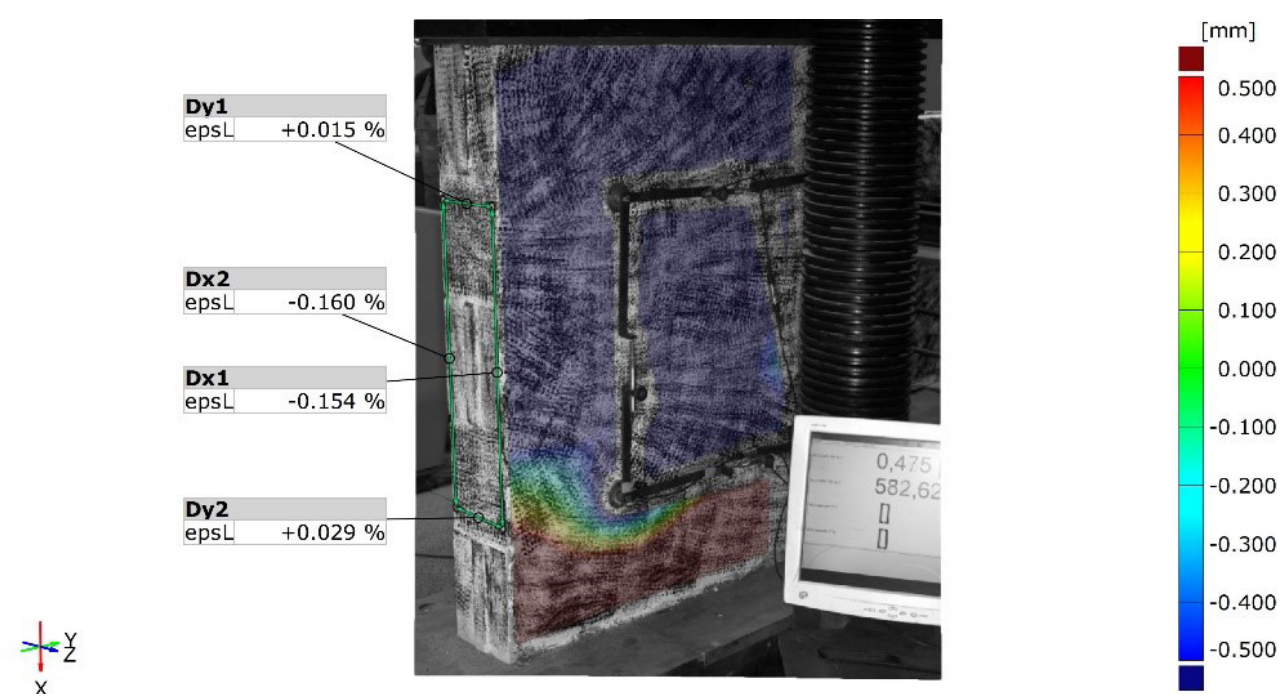

Fig. 8. Surface displacement on Z-axis in obtained from Aramis system for S1F1 1 test specimen. Source: own study

Inspections of damaged bottom areas of test specimens revealed failure occurred as the loosening of the strengthening with a part of masonry units.

\section{Conclusions}

One-side strengthening did not affect the load capacity of the masonry, and its increase by $6 \%$ was observed in the case of two-side strengthening test specimens. Characteristic compressive strength of the walls strengthened in one side was which determined in accordance with the standard [10] was lower by $1 \%$ when compared to the walls without any strengthening. In the case of the standard [13], the determined value was greater by $4 \%$ when compared to the walls without any strengthening. Characteristic strength values of the walls strengthened in two sides, determined with both methods were greater by $6 \%$ and $18 \%$ respectively for the standard [10] and [13] as compared to the unstrengthened walls. Considerable impact of the strengthening was found for cracking stresses. Crack resistance was improved by more than $10 \%$ in one-side strengthened test specimens, and by $17 \%$ in two-side strengthened test specimens. Strengthening did not significantly affect the modulus of elasticity but caused an increase in horizontal deformations of the masonry by ca. 50\%. The in-depth diagnosis of the effect exerted by applied strengthening on AAC masonry requires further studies. Therefore, 
the next stage of studies will include tests on one-side and two-side strengthened masonry for diagonal compression in accordance with the standard [6] and shearing in accordance with the standard [11].

\section{References}

[1] Babaeidarabad S., Arboleda D., Loreto G., Nanni A., "Shear strengthening of unreinforced concrete masonry walls with fabric-reinforced-cementitious-matrix", Construction and Building Materials, vol. 65, 2014, pp. 243-253.

[2] Ceroni F., Salzano P., "Design provisions for FRCM systems bonded to concrete and masonry elements", Composites Part B: Engineering, vol. 143, 2018, pp. 230-242. https://doi.org/10.1016/j. compositesb.2018.01.033

[3] Bilotta A., Ceroni F., Nigro E., Pecce M., "Experimental tests on FRCM strengthening systems for tuff masonry elements", Composits Part B: Engineering, vol. 129, 2017, pp. 251-270. https:// doi.org/10.1016/j.conbuildmat.2017.01.124

[4] Carozzi F.G. et al., "Experimental investigation of tensile and bond properties of Carbon-FRCM composites for strengthening masonry elements", Composites Part B, vol. 128, 2017, pp. 100-119.

[5] Jokiel R., Drobiec Ł., "Projektowanie wzmocnień konstrukcji murowych systemami FRCM w świetle badań i zaleceń normowych", Izolacje, vol. 3, 2019, pp. 90, 92-94.

[6] ASTM E519-81 Standard Test Method for Diagonal Tension (Shear) of Masonry Assemblages.

[7] Kubica J., Kałuża M., "Diagonally compressed AAC Block's masonry - effectiveness of strengthening using CRFP and GRFP laminates", in Proceedings $8^{\text {th }}$ International Masonry Conference, Masonry (11). Ed. by W. Jäger, B. Haseltine \& A. Fried, Dresden 2010, pp. 419-428.

[8] Kałuża M., Kubica J., "Behaviour of unreinforced and reinforced masonry wallettes made of ACC blocks subjected to diagonal compression", Technical Transactions - Civil Engineering 1-B/2013 (2013), pp. 79-94.

[9] Kałuża M., Galman I., Kubica J., Agneloni C., "Diagonal Tensile Strength of AAC Blocks Masonry with Thin Joints Superficially Strengthened by Reinforced Using GFRP Net Plastering", Key Engineering Materials, vol. 624, 2015, pp. 363-370. https://doi.org/10.4028/www.scientific.net/ KEM.624.363

[10] PN-EN 1052-1:2000 Methods of test for masonry - Part 1: Determination of compressive strength.

[11] PN-EN 1052-3:2004 Methods of test for masonry - Part 3: Determination of initial shear strength.

[12] Jasiński R., Drobiec Ł., "Study of Autoclaved Aerated Concrete Masonry Walls with Horizontal Reinforcement under Compression and Shear", Procedia Engineering, vol. 161, 2016, pp. 918-924. https://doi.org/10.1016/j.proeng.2016.08.758

[13] PN-EN 1990:2004 Eurocode - Basis of structural design. 